\title{
CARACTERÍSTICAS DA FLORA ARBÓREA DE QUATRO ESCOLAS DE PATO BRANCO-PR
}

Danielle Acco Cadorin ${ }^{1}$; Ionete Hasse ${ }^{2}$; Lenir Maristela Silva ${ }^{3}$; Celso Ferraz Bett ${ }^{4}$

(recebido em 18.11.2010 e aceito para publicação em 08.07.2011)

\section{RESUMO}

Este trabalho apresenta os resultados e a análise dos inventários da flora arbórea feitos no Colégio Estadual La Salle, Colégio Estadual Professor Agostinho Pereira, Colégio Estadual Castro Alves e Escola São Caetano - Irmãs Teatinas de Pato Branco - PR. Foram inventariados 462 indivíduos arbóreos vivos que contabilizaram 49 espécies identificadas e 7 não identificadas. A análise dos resultados obtidos mostra que das 49 espécies identificadas, 20 são nativas do Brasil e 11 pertencem à Floresta Ombrófila Mista, ecossistema da Mata Atlântica (bioma local). Nas escolas La Salle, Professor Agostinho Pereira, Castro Alves e São Caetano - Irmãs Teatinas, ocorreram, respectivamente, $33,72 \%, 32,77 \%$, 27,96\% e 20,80\% de freqüência de indivíduos nativos do Brasil. As três espécies com maior ocorrência nas quatro escolas foram: Ligustrum lucidum (ligustro), Citrus sp. (citros) e Cupressus sp. (cipreste). Dessas espécies, Ligustrum lucidum (ligustro) é a mais freqüentemente encontrada nas quatro escolas, responsável por $14,9 \%$ da flora arbórea das mesmas. Apenas $4,33 \%$ dos espécimes inventariados apresentaram presença de epífitas.

Palavras-chave: Pátios escolares; Arborização; Ligustrum lucidum.

\footnotetext{
${ }^{1}$ Acadêmica do Curso de Agronomia, UTFPR, Pato Branco/PR, danikadorin@hotmail.com

${ }^{2}$ Bióloga, Instituto Federal de Educação, Ciência e Tecnologia do Paraná, Campus Paranaguá, PR, ionete.hasse@ifpr.edu.br

${ }^{3}$ Bióloga, Universidade Federal do Parana, Matinhos, PR, lenirsilva@ufpr.br

${ }^{4}$ Acadêmico do Curso de Agronomia, UTFPR, Pato Branco/PR
} 


\section{CHARACTERISTICS OF ARBOREAL FLORA OF FOUR SCHOOLS OF PATO BRANCO,}

PR

\section{ABSTRACT}

This work presents the analysis and results of arboreal flora inventories did at La Salle State School, Professor Agostinho Pereira State School, Castro Alves State School and São Caetano School - Irmãs Teatina in Pato Branco - State of Paraná. It was inventoried 462 individuals living trees which accounted for 49 identified species and 7 unidentified ones. The analysis results shows that from 49 identified species, 20 are native from Brazil and 11 belong to Araucaria Forest an ecosystem from Atlantic Forest (a local biome). At La Salle, Professor Agostinho Pereira, Castro Alves Schools, and São Caetano - Irmãs Teatinas, occurred respectively, $33.72 \%, 32.77 \%, 27.96 \%$ and $20.80 \%$ frequency of native individuals from Brazil. The three most common species in the four schools were: Ligustrum lucidum (privet), Citrus sp. (citrus) and Cupressus sp. (cypress). From these species, Ligustrum lucidum (privet) is the most frequently found in the four schools, representing $14.9 \%$ of arboreal flora of them. Only $4.33 \%$ of specimens inventoried presented epiphytes presence.

Keywords: School yards, Trees, Ligustrum lucidum.

\section{INTRODUÇÃO}

A elevada e crescente densidade demográfica, a concentração de áreas construídas, o aumento de pavimentação asfáltica do solo e de áreas industriais tem tornaram-se características cada vez mais marcantes das cidades. Todos estes fatores podem gerar mudanças funcionais dos centros urbanos, como grandes superfícies impermeabilizadas, alterações no clima local causadas por elevado índice de reflexão, grande absorção de radiação solar diurna e diminuição da umidade relativa do ar. Como conseqüência, ocorre aumento nos valores da temperatura e concentração de poluentes. Nesse contexto, onde os fatores negativos se somam, pode haver considerável diminuição na qualidade de vida humana (BIONDI e ALTHAUS, 2005).

Estudos vêm mostrando que as áreas verdes assumem um papel importante na melhoria da qualidade ambiental das cidades. A capacidade que a vegetação possui em

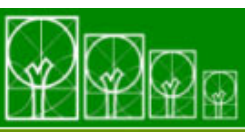

$\mathbf{S} \cdot \mathbf{B} \cdot \mathbf{A} \cdot \mathbf{U}$ Soc. Bras. de Arborização Urbana 
melhorar as condições do clima local está relacionada à sua atuação em promover um equilíbrio entre solo, clima, e vegetação, suavizando temperaturas elevadas através da diminuição da reflexão de radiações, aumentando a umidade atmosférica e conservando a umidade do solo (BIONDI e ALTHAUS, 2005).

A arborização tem a capacidade de diminuir a poluição através da retenção de partículas de poeira em suspensão. Folhas, galhos e troncos removem material sólido ou líquido particulado do ar. A remoção de gases tóxicos existentes na atmosfera pelas plantas ocorre quando esses gases se encontram retidos no material particulado, sendo filtrados conjuntamente. A vegetação arbórea urbana também pode ser responsável pela redução dos níveis de poluição sonora, através da absorção e refração de ondas sonoras (SANTOS e TEIXEIRA, 2001).

A flora arbórea, especialmente nos pátios escolares, pode trazer benefícios que vão além da melhoria da qualidade ambiental, servindo inclusive como instrumento de aprendizagem. Pode ser usada para ilustrar conhecimentos teóricos e ser uma ferramenta na educação ambiental, ensino da fenologia das espécies - principalmente as nativas, sobre o dinamismo na paisagem, interações flora-fauna, e importância histórica e econômica de algumas espécies importantes para a região como a araucária e a erva mate. É possível que os pátios das escolas disponham de uma arborização que represente a biodiversidade brasileira e expresse valores da cultura local.

Nesse sentido, é interessante que as árvores dos pátios escolares sejam nativas do bioma local, que tenham características do país tropical que é o Brasil, como, por exemplo, conter epífitas (bromélias, orquídeas, pteridófitas, dentre outras) (REIS, et al. 2003).

$\mathrm{Na}$ escolha das espécies dos pátios escolares, muitas vezes, faz-se uso de espécies exóticas, ou seja, com origem em outro território. Um dos efeitos não intencionais da introdução de espécies exóticas é que estas podem tornar-se invasoras. Espécies exóticas invasoras são aquelas que não sendo originárias de um determinado ambiente ou ecossistema, nele se estabelecem após serem introduzidas pela ação humana ou por fatores naturais, passando a se reproduzirem e dispersarem neste novo ambiente sem a ajuda direta do homem. Indiretamente ao modificar os ambientes naturais, por exemplo, ocupando e desmatando uma região, o homem pode facilitar a dispersão de espécies exóticas invasoras (IBGE, 2004).

O Brasil é um dos 12 países dotados da chamada megadiversidade. Em conjunto esses países abrigam $70 \%$ de toda a biodiversidade do planeta. Este é um patrimônio de inestimável valor biológico. As espécies exóticas invasoras competem com as espécies

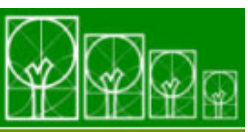

$\mathbf{S} \cdot \mathbf{B} \cdot \mathbf{A} \cdot \mathbf{U}$ Soc. Bras. de Arborização Urbana 
nativas, podendo causar a extinção de algumas delas. Entre as espécies invasoras há aquelas que, embora nativas do Brasil ou da América do Sul, são invasoras no bioma, ecossistema ou ambiente para onde foram transplantadas pela ação humana voluntária ou de forma acidental (IBGE, 2004).

Devido ao importante papel na formação infantil, a escola é considerada um dos principais elementos do ambiente social da criança e do jovem. Atuando de modo nãoverbal, o meio físico e biológico tem impacto direto e simbólico sobre os seus ocupantes, facilitando e/ou inibindo comportamentos. Na escola, esse meio possibilita a decodificação e a aprendizagem até mesmo de normas sociais, comunicando não-verbalmente aos estudantes as intenções e os valores dos professores enquanto adultos que exercem controle sobre o espaço (ELALI, 2003).

A integração do homem com o meio ambiente contribui para o seu bem estar e também para a sua própria formação. A biodiversidade deve ser reconhecida como valor cultural dentro do meio urbano e não apenas em paisagens externas a este (REIS et al. 2003). O investimento na educação na interface natureza/sociedade é estratégico na condução do processo de transição para uma sociedade sustentável (LEFF, 1995).

As concepções de natureza estabelecidas pela sociedade são produtos da cultura humana interagindo com o ambiente em que coexistiram, e isso varia conforme os valores que se estabelecem em determinado local (RIBEIRO, 2003). Portanto, sendo a escola um dos principais elementos do ambiente social da criança e do jovem e o principal local de transmissão/assimilação da cultura humana é imprescindível que o meio ambiente escolar de modo geral, receba especial atenção de pesquisadores.

Nos pátios escolares a arborização desempenha um papel que vai além da melhoria ambiental, podendo servir de modelo e de fonte contínua de aprendizado. Fedrizzi et al. (2008) cita que a melhoria da qualidade dos pátios escolares constitui uma importante alternativa no sentido de tornar as escolas locais mais atrativas e aprazíveis para a comunidade escolar como um todo. A vegetação bem planejada é um dos elementos que mais colabora para melhorar a qualidade destes espaços, agregando valores estéticos aos mesmos, melhorando suas condições de conforto e, ainda, servindo como uma valiosa ferramenta de apoio ao trabalho de educação ambiental.

O objetivo geral deste trabalho foi realizar o inventário da flora arbórea do pátio de quatro escolas de Pato Branco/PR, apontar problemas e soluções nas perspectivas ambiental, cultural e educativa.

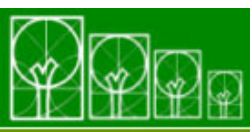

$\mathbf{S} \cdot \mathbf{B} \cdot \mathbf{A} \cdot \mathbf{U}$ Soc. Bras. de Arborização Urbana 


\section{MATERIAIS E MÉTODOS}

As escolas selecionadas encontram-se localizadas próximas aos bairros de Pato Branco/PR que já foram inventariados, dando-se preferência às escolas públicas. Diante disso, foram selecionadas três escolas públicas (Colégio Estadual Professor Agostinho Pereira, Colégio Estadual La Salle, Colégio Estadual Castro Alves) e uma escola privada (Escola São Caetano - Irmãs Teatinas) para serem inventariadas.

Pato Branco localiza-se na região sudoeste do Paraná, no terceiro planalto paranaense. Apresenta a ocorrência de $\mathrm{Cfa}$ - clima subtropical úmido mesotérmico (IAPAR, 2000), destacando-se o solo do tipo latossolo vermelho distroférrico (EMBRAPA, 1999). Pato Branco encontra-se a 760 m de altitude, com latitude de 26ำ 13' 46"S e longitude de 52 40’14” W-GR (IBGE, 2000).

A região na qual se localiza a área urbana do município era originariamente coberta por Floresta Ombrófila Mista Montana. Esta formação ocupa as regiões planálticas do Paraná, apresentando faixa de ocorrência altitudinal entre 400 e 1.000 metros. O dossel contínuo varia em torno de 20 metros de altura, mas as araucárias atingem até 25 metros. A Floresta Ombrófila Mista também é conhecida por "Floresta de Pinheiros", "Pinheirais", "Zona dos Pinhais", "Matas de Araucária" e "Florestas com Araucária" (IBGE, 1992).

Todas as escolas que foram inventariadas atendem a Educação Básica. O Colégio Estadual Professor Agostinho Pereira localiza-se no bairro Centro e foi fundado em 1943. O Colégio Estadual La Salle localiza-se no bairro La Salle e foi fundado em 1967. O Colégio estadual Castro Alves localiza-se no bairro Centro e foi fundado em 1977. A escola São Caetano - Irmãs Teatinas localiza-se no bairro Parzianello e foi fundada em 1973.

Os parâmetros para a realização do inventário foram indicados em planilha. A freqüência relativa de cada espécie foi calculada através da razão entre o número de indivíduos da espécie e o número total de indivíduos da escola, multiplicada por 100.

\section{RESULTADOS E DISCUSSÃO}

Nas quatro escolas inventariadas foram encontrados 462 indivíduos arbóreos vivos, que contabilizaram 49 espécies identificadas e 7 não identificadas.

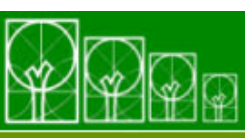

$\mathbf{S} \cdot \mathbf{B} \cdot \mathbf{A} \cdot \mathbf{U}$ Soc. Bras. de Arborização Urbana 
Sabe-se que a diversidade de espécies é um fator determinante para a qualidade ambiental do meio urbano. Contudo, são escassos os estudos com propostas de um método padrão para tal medida nas cidades e não existem dados específicos para ambientes escolares. Grey e Deneke (1986) sugeriram um nível de diversidade de espécies na arborização viária , em que uma única espécie não deve exceder o total de 10 a 15\% de uma população arbórea no ambiente urbano. Considerando este nível também em pátios de escolas, é possível constatar que algumas espécies tiveram freqüência elevada (Tabela 1, 2, 3 e 4), principalmente o ligustro no Colégio Estadual La Salle, pois este é responsável por 43,67\% da arborização da escola. A freqüência de indivíduos por espécies em uma determinada área, expressa uma relação de equabilidade dentro de um universo amostral. Em um ambiente onde predominam poucas espécies, a arborização estará mais suscetível ao ataque de pragas e doenças (BIONDI e ALTHAUS, 2005).

Tabela 1 - Frequência das espécies presentes na flora arbórea do colégio estadual La Salle de Pato Branco - PR/2008.

Table 1 - Frequency of species present in arboreal flora of La Salle State School in Pato Branco - State of Paraná - 2008.

\begin{tabular}{|c|c|c|c|c|}
\hline Nome Vulgar & Nome Científico & Origem & $\begin{array}{c}\mathbf{N}^{\circ} \text { de } \\
\text { Espécimes }\end{array}$ & Frequência \\
\hline Ligustro & $\begin{array}{c}\text { Ligustrum lucidum } \\
\text { W. T. Aiton }\end{array}$ & Ásia & 38 & $43,67 \%$ \\
\hline $\begin{array}{l}\text { Aroeira } \\
\text { Vermelha }\end{array}$ & $\begin{array}{c}\text { Schinus } \\
\text { terebinthifolius } \\
\text { Raddi } \\
\end{array}$ & Brasil & 12 & $13,79 \%$ \\
\hline Camélia & Camellia japonica L. & Ásia & 6 & $6,89 \%$ \\
\hline Cerejeira & $\begin{array}{c}\text { Eugenia involucrata } \\
D C .\end{array}$ & Brasil & 4 & $4,59 \%$ \\
\hline Jabuticaba & $\begin{array}{l}\text { Plinia trunciflora } \\
\text { (O.Berg) Kausel. }\end{array}$ & Brasil & 4 & $4,59 \%$ \\
\hline Araçá & $\begin{array}{c}\text { Psidium cattleianum } \\
\text { Sabine }\end{array}$ & Brasil & 3 & $3,45 \%$ \\
\hline Cedro & Cedrela fissilis Vell. & Brasil & 3 & $3,45 \%$ \\
\hline Cipreste & Cupressus sp. & Ásia & 3 & $3,45 \%$ \\
\hline Citrus & Citrus sp. & Ásia & 2 & $2,30 \%$ \\
\hline
\end{tabular}




\begin{tabular}{|c|c|c|c|c|}
\hline Ipê Amarelo & $\begin{array}{c}\text { Tabebuia } \\
\text { chrysotricha (Mart. } \\
\text { ex. DC.) Standl. }\end{array}$ & Brasil & 2 & $2,30 \%$ \\
\hline Algodoeiro & Gossypium sp. & Brasil & 1 & $1,15 \%$ \\
\hline $\begin{array}{l}\text { Bico de } \\
\text { Papagaio }\end{array}$ & $\begin{array}{c}\text { Euphorbia } \\
\text { pulcherrima Willd }\end{array}$ & $\begin{array}{c}\text { América do } \\
\text { Norte e } \\
\text { México } \\
\end{array}$ & 1 & $1,15 \%$ \\
\hline Cinamomo & Melia azedarach L. & Austrália & 1 & $1,15 \%$ \\
\hline Goiabeira & Psidium guajava L. & $\begin{array}{l}\text { México e } \\
\text { norte da } \\
\text { América }\end{array}$ & 1 & $1,15 \%$ \\
\hline Ipê Roxo & $\begin{array}{c}\text { Tabebuia } \\
\text { heptaphylla (Vell.) } \\
\text { Tol. }\end{array}$ & Brasil & 1 & $1,15 \%$ \\
\hline Nêspera & $\begin{array}{l}\text { Eriobotrya japonica } \\
\text { (Thunb.) Lindl. }\end{array}$ & China & 1 & $1,15 \%$ \\
\hline Pessegueiro & $\begin{array}{c}\text { Prunus persica (L.) } \\
\text { Batsch }\end{array}$ & China & 1 & $1,15 \%$ \\
\hline Pitangueira & Eugenia uniflora $L$. & Brasil & 1 & $1,15 \%$ \\
\hline Sanguínea & $\begin{array}{c}\text { Euphorbia cotinifolia } \\
L .\end{array}$ & América & 1 & $1,15 \%$ \\
\hline Yucca & Yucca sp. & $\begin{array}{c}\text { América do } \\
\text { Norte }\end{array}$ & 1 & $1,15 \%$ \\
\hline \multicolumn{3}{|c|}{ Total de espécimes } & 86 & $100 \%$ \\
\hline
\end{tabular}

Tabela 2 - Frequência das espécies presentes na flora arbórea do colégio estadual professor Agostinho Pereira de Pato Branco - PR/2008.

Table 2 - Frequency of species present in arboreal flora of Professor Agostinho Pereira State School in Pato Branco - State of Paraná - 2008.

\begin{tabular}{c|c|c|c|c}
\hline Nome Vulgar & $\begin{array}{c}\text { Nome Científico } \\
\text { Extremosa }\end{array}$ & $\begin{array}{c}\text { Lagerstroemia indica } \\
\text { L. }\end{array}$ & $\begin{array}{c}\mathbf{N}^{\circ} \text { de } \\
\text { Espécimes }\end{array}$ & Frequência \\
\hline Pata de Vaca & Bauhinia variegata L. & 17 & $29,31 \%$ \\
\hline Índia, China & 6 & $10,34 \%$ \\
\hline Ipê Amarelo & $\begin{array}{c}\text { Lafoensia pacari St, } \\
\text { Hil. }\end{array}$ & Brasil & 4 & $6,9 \%$ \\
\hline
\end{tabular}




\begin{tabular}{|c|c|c|c|c|}
\hline & ex. DC.) Standl. & & & \\
\hline Pau Brasil & $\begin{array}{c}\text { Caesalpinia echinata } \\
\text { Lam. }\end{array}$ & Brasil & 4 & $6,9 \%$ \\
\hline Citros & Citrus sp. & Ásia & 3 & $5,17 \%$ \\
\hline Tipuana & $\begin{array}{l}\text { Tipuana tipu (Benth.) } \\
\text { Kuntz }\end{array}$ & $\begin{array}{l}\text { Bolívia, } \\
\text { Argentina }\end{array}$ & 3 & $5,17 \%$ \\
\hline Araticum & $\begin{array}{c}\text { Rollinia silvatica (St. } \\
\text { Hil.) Mart. }\end{array}$ & Brasil & 2 & $3,45 \%$ \\
\hline Aroeira & Schinus molle $L$. & Brasil & 2 & $3,45 \%$ \\
\hline Canafístula & $\begin{array}{l}\text { Peltophorum dubium } \\
\text { (Spreng.) Taub. }\end{array}$ & Brasil & 2 & $3,45 \%$ \\
\hline Pessegueiro & $\begin{array}{c}\text { Prunus persica (L.) } \\
\text { Batsch }\end{array}$ & China & 2 & $3,45 \%$ \\
\hline Azaléia & $\begin{array}{c}\text { Rhododendron } \\
\text { xsismii }\end{array}$ & China & 1 & $1,72 \%$ \\
\hline Ligustro & $\begin{array}{c}\text { Ligustrum lucidum W. } \\
\text { T. Aiton }\end{array}$ & Ásia & 1 & $1,72 \%$ \\
\hline Mamão & Carica papaya L. & $\begin{array}{l}\text { América do } \\
\text { Sul }\end{array}$ & 1 & $1,72 \%$ \\
\hline Nêspera & $\begin{array}{l}\text { Eriobotrya japonica } \\
\text { (Thunb.) Lindl. }\end{array}$ & China & 1 & $1,72 \%$ \\
\hline Quaresmeira & $\begin{array}{l}\text { Tibouchina granulosa } \\
\text { Cogn. }\end{array}$ & Brasil & 1 & $1,72 \%$ \\
\hline \multicolumn{3}{|c|}{ Total de espécimes } & 54 & $100 \%$ \\
\hline
\end{tabular}

Tabela 3 - Frequência das espécies presentes na flora arbórea do colégio estadual Castro Alves de Pato Branco - PR/2008.

Table 3 - Frequency of species present in arboreal flora of Castro Alves State School in Pato Branco - State of Paraná - 2008.

\begin{tabular}{c|c|c|c|c}
\hline Nome Vulgar & Nome Científico & Origem & $\begin{array}{c}\mathbf{N}^{\circ} \text { de } \\
\text { Espécimes }\end{array}$ & Frequência \\
\hline Cipreste & Cupressus sp. & Ásia & 34 & $28,81 \%$ \\
\hline Ligustro & $\begin{array}{c}\text { Ligustrum lucidum W. } \\
\text { T. Aiton }\end{array}$ & Ásia & 20 & $16,95 \%$ \\
\hline Araucária & $\begin{array}{c}\text { Araucaria angustifolia } \\
\text { (Bertol.) Kuntze }\end{array}$ & Brasil & 16 & $13,56 \%$ \\
\hline Pata de Vaca & Bauhinia variegata L. & Índia, China & 12 & 10,17 \\
\hline
\end{tabular}




\begin{tabular}{|c|c|c|c|c|}
\hline Ipê Amarelo & $\begin{array}{c}\text { Tabeuia alba (Cham.) } \\
\text { Sandw. }\end{array}$ & Brasil & 7 & $5,93 \%$ \\
\hline Citros & Citrus sp. & Ásia & 7 & $5,93 \%$ \\
\hline Araçá & $\begin{array}{c}\text { Psidium cattleianum } \\
\text { Sabine }\end{array}$ & Brasil & 3 & $2,54 \%$ \\
\hline Café & Coffea arabica $L$ & África & 3 & $2,54 \%$ \\
\hline Cáqui & Diospyros kaki L. F. & Ásia & 3 & $2,54 \%$ \\
\hline Ipê Amarelo & $\begin{array}{c}\text { Tabebuia } \\
\text { chrysotricha (Mart. } \\
\text { ex. DC.) Standl. }\end{array}$ & Brasil & 3 & $2,54 \%$ \\
\hline Canafístula & $\begin{array}{l}\text { Peltophorum dubium } \\
\text { (Spreng.) Taub. }\end{array}$ & Brasil & 2 & $1,69 \%$ \\
\hline Pêra & Pyrus sp. & Ásia & 2 & $1,69 \%$ \\
\hline Pitangueira & Eugenia uniflora $L$. & Brasil & 2 & $1,69 \%$ \\
\hline Abacateiro & $\begin{array}{c}\text { Persea americana } \\
\text { Mill. }\end{array}$ & América & 1 & $0,85 \%$ \\
\hline Amoreira & Morus alba L. & $\begin{array}{c}\text { Ásia, África } \\
\text { e América } \\
\text { do Norte }\end{array}$ & 1 & $0,85 \%$ \\
\hline Butiá & Butia sp. & $\begin{array}{l}\text { América do } \\
\text { Sul }\end{array}$ & 1 & $0,85 \%$ \\
\hline Grevílea & $\begin{array}{l}\text { Grevillea robusta } A . \\
\text { Cunn. Ex R. Br. }\end{array}$ & Austrália & 1 & $0,85 \%$ \\
\hline \multicolumn{3}{|c|}{ Total de espécimes } & 118 & $100 \%$ \\
\hline
\end{tabular}

Tabela 4 - Frequência das espécies presentes na flora arbórea da escola São Caetano Irmãs Teatinas de Pato Branco - PR/2008.

Table 4 - Frequency of species present in arboreal flora of Sao Caetano School - Irmãs Teatinas in Pato Branco - State of Paraná - 2008.

\begin{tabular}{c|c|c|c|c}
\hline Nome Vulgar & Nome Científico & Origem & $\begin{array}{c}\mathbf{N}^{\circ} \text { de } \\
\text { Espécimes }\end{array}$ & Frequência \\
\hline Citros & Citrus sp. & Ásia & 36 & $19,14 \%$ \\
\hline Pessegueiro & $\begin{array}{c}\text { Prunus persica (L.) } \\
\text { Batsch }\end{array}$ & China & 21 & $11,17 \%$ \\
\hline Bananeira & Musa sp. & Ásia & 15 & $7,97 \%$ \\
\hline
\end{tabular}




\begin{tabular}{|c|c|c|c|c|}
\hline Ipê amarelo & $\begin{array}{l}\text { Tabeuia alba (Cham.) } \\
\text { Sandw. }\end{array}$ & Brasil & 13 & $6,91 \%$ \\
\hline Jabuticabeira & $\begin{array}{l}\text { Plinia trunciflora } \\
\text { (O.Berg) Kausel. }\end{array}$ & Brasil & 12 & $6,38 \%$ \\
\hline Goiabeira & Psidium guajava L. & $\begin{array}{c}\text { México e } \\
\text { Norte da } \\
\text { América do } \\
\text { Sul }\end{array}$ & 11 & $5,85 \%$ \\
\hline Nêspera & $\begin{array}{l}\text { Eriobotrya japonica } \\
\text { (Thunb.) Lindl. }\end{array}$ & China & 10 & $5,31 \%$ \\
\hline Ligustro & $\begin{array}{c}\text { Ligustrum lucidum W. } \\
\text { T. Aiton }\end{array}$ & Ásia & 10 & $5,31 \%$ \\
\hline Caqui & Diospyros kaki L. F. & Ásia & 7 & $3,72 \%$ \\
\hline Cerejeira & $\begin{array}{c}\text { Eugenia involucrata } \\
D C .\end{array}$ & Brasil & 7 & $3,72 \%$ \\
\hline Eucalipto & Eucalyptus sp. & Oceania & 7 & $3,72 \%$ \\
\hline Figueira & Fícus carica & $\begin{array}{l}\text { Oriente } \\
\text { Médio }\end{array}$ & 6 & $3,19 \%$ \\
\hline Camélia & Camellia japonica L. & Ásia & 5 & $2,65 \%$ \\
\hline Abacateiro & $\begin{array}{c}\text { Persea americana } \\
\text { Mill. }\end{array}$ & América & 4 & $2,12 \%$ \\
\hline Tipuana & $\begin{array}{c}\text { Tipuana tipu (Benth.) } \\
\text { Kuntz } \\
\end{array}$ & $\begin{array}{c}\text { Bolívia, } \\
\text { Argentina }\end{array}$ & 4 & $2,07 \%$ \\
\hline Cipreste & Cupressus sp. & Ásia & 3 & $1,59 \%$ \\
\hline Mamão & Carica papaya L. & $\begin{array}{l}\text { América do } \\
\text { Sul }\end{array}$ & 3 & $1,59 \%$ \\
\hline $\begin{array}{c}\text { Aroeira } \\
\text { Vermelha }\end{array}$ & $\begin{array}{c}\text { Schinus } \\
\text { terebinthifolius Raddi }\end{array}$ & Brasil & 2 & $1,06 \%$ \\
\hline $\begin{array}{c}\text { Pata de Vaca } \\
\text { do Mato }\end{array}$ & $\begin{array}{l}\text { Bauhinia forficata } \\
\text { Link }\end{array}$ & Brasil & 2 & $1,06 \%$ \\
\hline Yucca & Yucca sp. & $\begin{array}{c}\text { México e } \\
\text { América do } \\
\text { Norte }\end{array}$ & 2 & $1,06 \%$ \\
\hline Araçá & $\begin{array}{c}\text { Psidium cattleianum } \\
\text { Sabine }\end{array}$ & Brasil & 1 & $0,53 \%$ \\
\hline $\begin{array}{l}\text { Bico de } \\
\text { Papagaio }\end{array}$ & $\begin{array}{c}\text { Euphorbia } \\
\text { pulcherrima Willd }\end{array}$ & $\begin{array}{c}\text { América do } \\
\text { Norte e } \\
\text { México }\end{array}$ & 1 & $0,53 \%$ \\
\hline Grevilea & $\begin{array}{c}\text { Grevillea robusta } A . \\
\text { Cunn. Ex R. Br. }\end{array}$ & Austrália & 1 & $0,53 \%$ \\
\hline Palmeira & Syagrus sp. & América & 1 & $0,53 \%$ \\
\hline Primavera & Bougainvillea glabra & Brasil & 1 & $0,53 \%$ \\
\hline Araparirana & $\begin{array}{l}\text { Macrolobium bifolium } \\
\text { (Aubl.) Pers. }\end{array}$ & Brasil & 1 & $0,53 \%$ \\
\hline
\end{tabular}




\begin{tabular}{c|c|c|c|c}
\hline Sibipiruna & $\begin{array}{c}\text { Caesalpinia } \\
\text { peltophoroides Benth. }\end{array}$ & Brasil & 1 & $0,53 \%$ \\
\hline Pau Incenso & $\begin{array}{c}\text { Pittosporum } \\
\text { undulatum Vent. }\end{array}$ & Austrália & 1 & $0,53 \%$ \\
\hline \multicolumn{3}{c}{ Total de espécimes } & 188 & $100 \%$ \\
\hline
\end{tabular}

Constata-se que a escola que possui maior diversificação de espécies e maior número de espécimes é a escola São Caetano - Irmãs Teatinas, que possui em seu pátio 28 diferentes espécies arbóreas identificadas. Esta maior diversificação e número de espécimes deve-se ao fato da escola possuir um pomar em suas dependências. Neste pomar predominam as espécies frutíferas, onde estão presentes as bananeiras, cerejeiras, jabuticabeiras, caquizeiros, goiabeiras, pessegueiros, citros entre outras espécies.

Das 49 espécies identificadas nas quatro escolas, 21 são nativas e 28 são exóticas. Apesar de o número de espécies nativas representar $42,85 \%$ do total de espécies presentes nas quatro escolas, a freqüência de indivíduos arbóreos nativos é significativamente menor que a freqüência de indivíduos exóticos (Tabela 5).

TABELA 5 - Relação entre a frequência dos espécimes nativos e exóticos presentes nas escolas La Salle, Professor Agostinho Pereira, Castro Alves e Irmãs Teatinas - PR/2008.

TABLE 5 - Relationship between frequency of native and exotic specimens found in schools La Salle, Professor Agostinho Pereira, Castro Alves and Irmãs Teatinas - State of Paraná 2008.

\begin{tabular}{c|c|c}
\hline Escolas & Espécimes Nativos & Espécimes Exóticos \\
\hline La Salle & $33,72 \%$ & $66,28 \%$ \\
\hline Professor Agostinho Pereira & $32,77 \%$ & $67,23 \%$ \\
\hline Castro Alves & $27,96 \%$ & $72,04 \%$ \\
\hline São Caetano - Irmãs Teatinas & $20,8 \%$ & $79,2 \%$ \\
\hline
\end{tabular}

A Portaria do IAP №. 095, de 22 de maio de 2007 (IAP, 2007), define espécie exótica como qualquer espécie, subespécie ou táxon inferiores introduzidos fora da sua área natural de distribuição presente ou passada, incluindo qualquer parte, gametas, sementes, ovos ou propágulos dessas espécies que possam sobreviver e posteriormente reproduzir-se. 
Segundo Machado et al. (2006) a crescente substituição de espécies nativas por espécies exóticas nas cidades brasileiras altera o ambiente natural que resta dos centros urbanos. Este procedimento acaba por uniformizar a paisagem de diferentes cidades e contribuir para a redução da biodiversidade nestes ambientes, dissociando-se do contexto ambiental onde se insere. No sul do Brasil, o ligustro, por exemplo, foi amplamente utilizado por proporcionar sombra e apresentar rápido crescimento. Em sete bairros já inventariados em Pato Branco, cinco deles apresentaram predominância desta espécie que é responsável por 62,4\%, 40,65\%, 70,14\%, 45,75\%, e 47,29\% da arborização dos bairros Centro, Bancários, Brasília, Parzianello e La Salle, respectivamente. Em inventário das duas principais vias da cidade de Mariópolis, também localizada no sudoeste do Paraná, o ligustro apareceu como responsável por 54\% da arborização (CADORIN et al. 2008; RODIGHIERO et al. 2007; SILVA et al. 2007; SILVA et al. 2008).

Dentre as espécies exóticas presentes nas escolas, seis constam na lista de exóticas invasoras do Brasil (IAP, 2007), sendo estas: Ligustrum lucidum W. T. Aiton. (ligustro), Melia azedarach L. (cinamomo), Psidium guajava L. (goiabeira), Eriobotrya japonica (Thunb.) Lindl. (nêspera), Pittosporum undulatum Ventt. (pau incenso) e Eucalyptus sp. (eucalipto).

Segundo Ziller (2001) a introdução de plantas exóticas invasoras afeta o funcionamento do ecossistema, pois estas se adaptam e são capazes de reproduzir-se a ponto de ocupar o espaço das nativas, diminuindo a biodiversidade. O potencial de espécies exóticas de alterar sistemas naturais é tão grande que as plantas invasoras são hoje a segunda maior ameaça mundial à biodiversidade, perdendo somente para a destruição direta do homem. Os processos de invasão agravam-se à medida que as plantas exóticas ocupam o espaço das nativas. As conseqüências principais são a perda da biodiversidade e a modificação dos ciclos e características naturais dos ecossistemas atingidos, além da alteração fisionômica da paisagem natural.

A recomendação é que para plantios futuros nos pátios das escolas, seja dada preferência às espécies nativas da Mata Atlântica, para desta forma evitar a introdução de espécies que tenham potencial invasor. Recomenda-se também, que nos casos em que for possível, de forma planejada e gradativa, as espécies exóticas que constam na lista de invasoras sejam substituídas por espécies nativas. Essa é uma recomendação que consta na Portaria do IAP no. 095, de 22 de maio de 2007 (IAP, 2007), em que o artigo sexto determina que os imóveis públicos nos quais for constatada a presença de espécies exóticas invasoras procedam a sua erradicação, ou controle para evitar contaminação biológica.

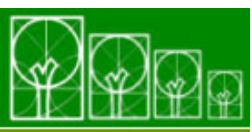

S $\cdot \mathbf{B} \cdot \mathbf{A} \cdot \mathbf{U}$ Soc. Bras. de Arborização Urbana 
As espécies mais abundantes inventariadas nas quatro escolas são Ligustrum lucidum W. T. Aiton. (ligustro), Citrus sp. (citrus), e Cupressus sp. (cipreste) que correspondem a 14,9\%, 10,38\% e $8,65 \%$ da soma dos espécimes das quatro escolas, respectivamente.

A espécie Ligustrum lucidum W. T. Aiton. (ligustro) é a espécie mais abundante na flora arbórea da escola La Salle correspondendo a 44,25\% da arborização do mesmo. Esta espécie também está presente na flora arbórea das outras três escolas, embora com menor freqüência. O ligustro é uma espécie exótica e consta na lista das espécies invasoras brasileiras (IAP, 2007).

Resultados de inventários realizados em bairros da cidade mostram a grande utilização desta espécie na cidade de Pato Branco. Dados do censo realizado no La Salle, bairro onde se insere a escola Colégio Estadual La Salle, mostram que quase metade da arborização viária do mesmo é composta pela espécie Ligustro lucidum W. T. Aiton. (CADORIN et al. 2008).

Esta espécie de origem asiática é amplamente usada nas cidades do sul do Brasil e foi introduzida no país para fins ornamentais. Sua dispersão ocorre de maneira rápida e é capaz de competir e impedir a regeneração de plantas nativas. Os frutos são tóxicos para os humanos e podem causar sintomas como náusea, dores de cabeça, dores abdominais, vômitos, diarréia, pressão baixa e hipotermia (INSTITUTO HÓRUS, 2006), mostrando - se, portanto, espécie inadequada para o uso em pátios escolares

Atualmente a espécie é uma invasora da Floresta Ombrófila Mista Aluvial no estado do Paraná e está em processo de dominância de várias áreas de floresta ciliar da região (INSTITUTO HÓRUS, 2006).

As espécies de citros são também exóticas, porém, não apresentam potencial invasor no bioma local. O gênero Citrus tem como centro de origem a Ásia, porém se encontra em várias regiões em todo mundo. No Brasil, as plantas cítricas foram introduzidas pelas primeiras expedições colonizadoras, provavelmente na Bahia. No Brasil, com melhores condições para vegetar e produzir do que nas próprias regiões de origem, os citros se expandiram para todo o país (BACKES e IRGANG, 2004).

As espécies do gênero Cupressus (ciprestes) também não são nativas do Brasil, sendo originárias da Ásia. Estas também não apresentam potencial invasor, e foram introduzidas no sul do Brasil pelos portugueses principalmente com fins ornamentais (BACKES e IRGANG, 2004).

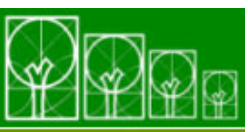

$\mathbf{S} \cdot \mathbf{B} \cdot \mathbf{A} \cdot \mathbf{U}$ Soc. Bras. de Arborização Urbana 
A vegetação é considerada um verdadeiro laboratório vivo para aulas práticas da educação formal e informal, além de servir ao uso dos diferentes segmentos de ensino público ou privado (MELO e SEVERO, 2007).

De acordo com os parâmetros curriculares nacionais do Ministério de Educação do Brasil (MELO e SEVERO, 2007), no meio ambiente, em termos educativos, vários temas podem ser estudados. As visitas às áreas naturais podem e devem ser feitas da pré-escola à Universidade, procurando a perfeita integração.

Segundo Filho et al. (2001) no desenho da malha urbana, os espaços livres devem ser concebidos de modo que expressem um real atendimento às necessidades sociais e ambientais. Contudo, não é isto que tem sido verificado no país, já que ruas, praças, e demais logradouros públicos seguem formas de organização morfológica bastante similar, apesar das diferenças regionais, com fatores sociais e ambientais bem diversificados. $O$ autor afirma ainda, que, neste sentido os espaços públicos e áreas verdes podem exercer um papel importante na identidade dos lugares.

Percebe-se, portanto, que as espécies nativas da Mata Atlântica podem ser importantes no processo de ensino aprendizagem de várias áreas do conhecimento nas escolas inventariadas.

Das 21 espécies nativas, 11 pertencem ao ecossistema local (Floresta Ombrófila Mista) sendo: Schinus terebinthifolius Raddi. (Aroeira Vermelha), Schinus molle L. (Aroeira Mole), Plinia trunciflora (O.Berg) Kausel. (Jabuticabeira), Psidium cattleianum Sabine. (Araçá), Eugenia uniflora L. (Pitangueira), Eugenia involucrata DC. (Cerejeira), Lafoensia pacari St, Hil. (Dedaleiro), Rollinia silvatica (St. Hil.) Mart. (Araticum), Araucaria angustifolia (Bertol.) Kuntze. (Araucária), Bauhinia forficata Link. (Pata de Vaca do Mato) e Cedrela fissilis Vell. (Cedro).

Pode -se destacar, no caso da escola Castro Alves, a presença de araucárias (Figura 1), que aparecem isoladas ou agrupadas. Esta espécie é responsável por $13,56 \%$ da flora arbórea desta escola. Sua presença, segundo Melo e Severo (2007), resgata a cultura, a educação e a história, salvaguardando a vegetação característica regional nativa e preservando-a, visto que encontra-se nas listas de espécies ameaçadas.

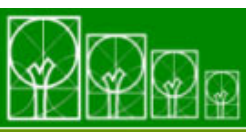




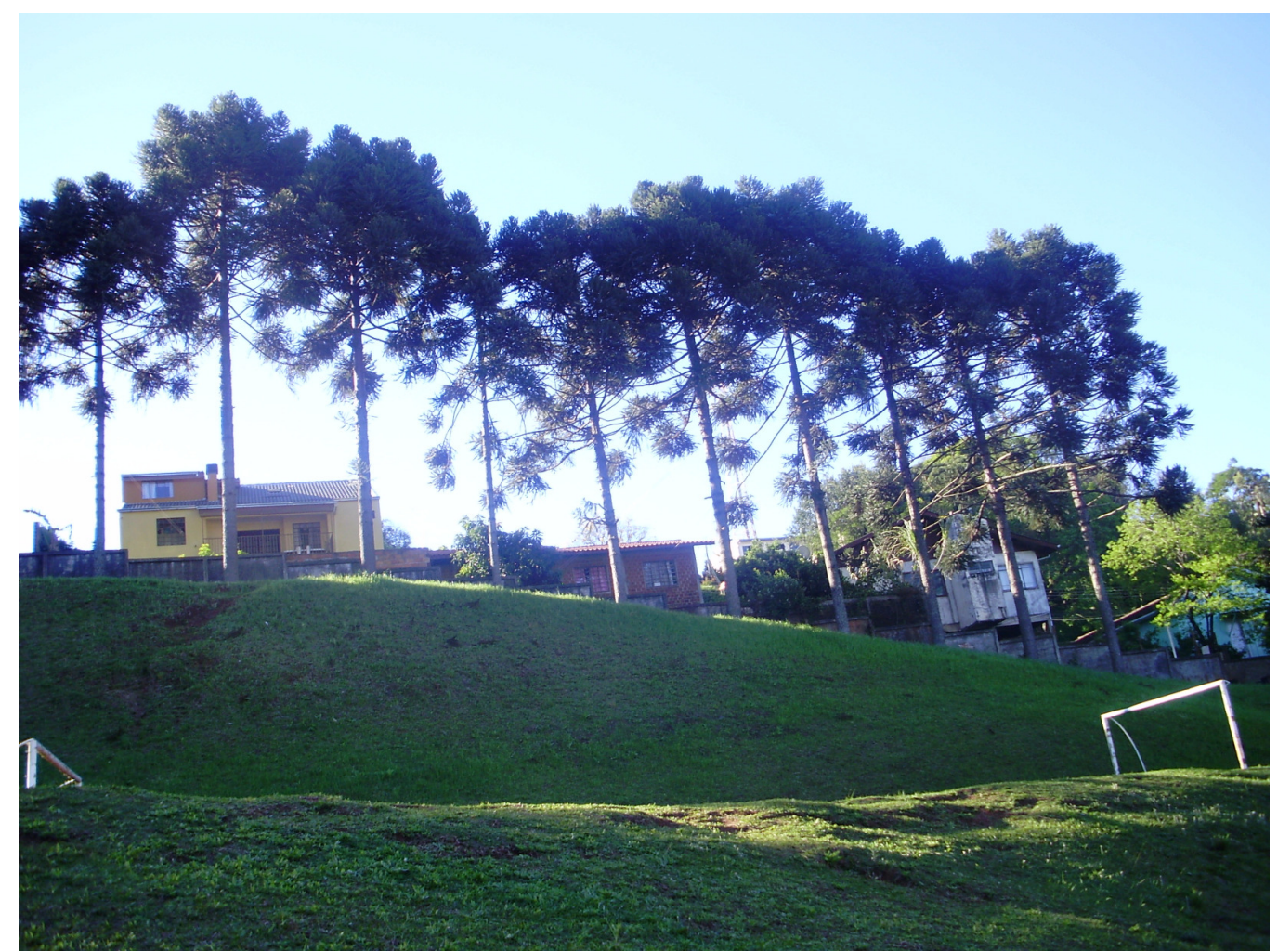

Figura 1 - Pátio do Colégio Estadual Castro Alves com a presença de Araucárias Araucaria angustifolia (Bertol.) Kuntze.

Figure 1 - Castro Alves State School yard with Araucaria trees - Araucaria angustifolia (Bertol.) Kuntze.

$\mathrm{Na}$ escola Professor Agostinho Pereira destaca - se a presença da espécie Lafoensia pacari St, Hil.; o dedaleiro, nativa da Floresta Ombrófila Mista. Esta espécie também é conhecida no Brasil, como amarelinho, ou louro - amarelo (CARVALHO, 2003).

Já na escola São Caetano - Irmãs Teatinas destacam - se as espécies nativas frutíferas, presentes principalmente no pomar da escola. A cerejeira do mato, jabuticaba e araçá são as principais. Espécies nativas frutíferas podem ajudar na manutenção de aves frugívoras, já que a produção dos frutos atrai populações de pássaros que por sua vez exercem ação efetiva na dispersão de sementes.

Quanto à presença de epífitas, estas foram encontradas em 21 indivíduos arbóreos, representando $4,33 \%$ do total de espécimes inventariados. Deste total, $60 \%$ dos forófitos são da espécie Tabebuia chrysotricha (Mart. ex. DC.) Standl., conhecido popularmente como Ipê Amarelo, e 20\% são da espécie Tipuana tipu (Benth.) Kuntz, a tipuana.

Os epífitos desenvolvem todo seu ciclo de vida, ou pelo menos parte dele, sobre outras plantas, utilizando somente o suporte mecânico de seus hospedeiros, sem a retirada 
direta de nutrientes $\left(\mathrm{MADISON}^{5} ; \mathrm{NADKARNI}^{6}\right.$; BENZING ${ }^{7}$ citados por GIONG e WAECHTER, 2004).

As plantas epifíticas representam aproximadamente $10 \%$ de toda a flora vascular mundial, porém, apesar do esforço crescente dos pesquisadores, especialmente na última década, o conhecimento acumulado a respeito destas plantas ainda é insuficiente diante da sua importância.

A epífita de maior ocorrência na flora arbórea das quatro escolas é a espécie Microgramma vaccinifolia chamada popularmente de samambaia - grama.

\section{Sugestões de espécies para as escolas inventariadas}

O Brasil apresenta seis Biomas distintos, sendo eles: Amazônia, Cerrado, Mata Atlântica, Caatinga, Pampa e Pantanal (IBGE, 2008). Em cada bioma, há mais de um perfil fitogeográfico, ou seja, existe mais de um tipo de vegetação. Com isso, há disponível em cada bioma uma grande variedade de espécies, sendo que, dessas, há várias espécies arbóreas com ótimas características paisagísticas.

Além do fator de beleza peculiar, há também a facilidade que essa espécie terá de se desenvolver num bioma que é próprio à sua espécie. Em contrapartida, a natureza ganha também, porque muitos animais, principalmente pássaros nativos, podem se tornar visitantes constantes (SILVA, 2008). Alguns autores recomendam também a utilização de espécies nativas que disponibilizem frutos comestíveis para a avifauna (PEREIRA, et al., 2005).

No caso da arborização de vias públicas, em que há mais informações quanto às espécies adequadas para o plantio, é evidente que muitas das espécies nativas não são indicadas devido ao grande porte que pode gerar confronto com a rede elétrica, raízes muito volumosas que geram atrito com as calçadas, grandes frutos ou galhos que invadem as vias, sendo que o uso de espécies nativas muitas vezes se restringe a árvores de pequeno e médio porte. Entretanto, no caso de pátios escolares, problemas como o atrito com a fiação elétrica, calçada, pedestres ou galhos invadindo as vias, quando existem, são muito menores, o que possibilita o uso de um maior número de espécies nativas, inclusive as de porte maior.

\footnotetext{
5 MADISON, M. 1977. Vascular epiphytes: their systematic occurrence and salient features. Selbyana 2:1-13.

${ }^{6}$ NADKARNI, N.M. 1985. An ecological overview and checklist of vascular epiphytes in the Monteverde cloud forest reserve, Costa Rica. Brenesia 24:55-62.

${ }^{7}$ BENZING, D.H. 1990. Vascular epiphytes: general biology and related biota. Cambridge University Press, Cambridge.
} 
A arborização dos pátios escolares com espécies nativas pode contribuir no processo ensino aprendizagem de várias maneiras: conhecimento das espécies do bioma local; estudo da fenologia das espécies nativas; estudo das interações flora-fauna (polinizadores, herbívoros, melíferos, granívoros, insetívoros e frugívoros); estudo das espécies arbóreas que representam importância nos aspectos históricos, sociais, culturais e econômicos do estado do Paraná como o Pinheiro do Paraná (Araucaria angustifolia (Bertol) Kuntze) e a Erva-mate (Ilex paraguariensis A. St.-Hil).

Nesse sentido, várias espécies nativas do bioma local podem ser implantadas nos pátios escolares como:

- Angico vermeho - Parapiptadenia rígida (Benth) Brenan

- Araçá - Psidium cattleianum Sabine

- Araucária - Araucaria angustifolia (Bertol.) Kuntze

- Aroeira mansa - Schinus molle L.

- Aroeira vermelha - Schinus terebinthifolius Raddi.

- Canafístula - Peltophorum dubium (Spreng.) Taub.

- Canela amarela - Nectandra lanceolata Nees.

- Cedro - Cedrela fissillis Vell.

- Cerejeira - Eugenia involucrata DC.

- Corticeira - Erythrina falcata Benth.

- Dedaleiro - Lafoensia pacari St. Hil.

- Embira branca - Daphnopsis racemosa Griseb.

- Erva mate - Ilex paraguariensis A. St.-Hil.

- Guamirim da folha fina - Myrcia rostrata DC.

- Jabuticabeira - Plinia trunciflora (O.Berg) Kausel.

- Jacarandá Branco - Jacaranda puberula Cham.

- Pata de Vaca do Mato - Bauhinia forficata Link

- Paineira - Chorisia peciosa A. St.-Hill.

- Pinho bravo - Podocarpus lambertti Klotzschi ex Endl.

- Pitanga - Eugenia uniflora L.

- Tambaratão - Zanthoxylum rhoifolium Lam.

- Uvaia- Eugenia uvalha Cambess.

- Vassourão Preto - Vernonia discolor (Spreng.) Less. 


\section{CONCLUSÕES}

Com o resultado do inventário da flora arbórea do pátio das quatro escolas de Pato Branco/PR, foi possível identificar o predomínio de espécies exóticas em relação às nativas. A análise dos dados mostra que das 49 espécies identificadas 21 são nativas e 28 são exóticas. Apesar de o número de espécies nativas representar $42,85 \%$ do total de espécies presentes nas quatro escolas, a freqüência de indivíduos arbóreos nativos é baixa em relação aos indivíduos exóticos sendo de 33,72\%, 32,77\%, 27,96\% e 20,8\% nas escolas Colégio Estadual La Salle, Colégio Estadual Professor Agostinho Pereira, Colégio Estadual Castro Alves e Escola São Caetano - Irmãs Teatinas, respectivamente.

Das 21 espécies nativas, 11 pertencem ao bioma local (Floresta Ombrófila Mista). Destaca-se a importância que essas espécies podem ter como ferramenta de ensino principalmente quanto aos aspectos culturais do Estado do Paraná, à exemplo do Pinheiro do Paraná e da Erva-Mate.

Das espécies exóticas, apenas seis constam na lista de exóticas invasoras do bioma local. As espécies mais abundantes inventariadas nas quatro escolas são Ligustrum lucidum W. T. Aiton. (ligustro), Citrus sp. (citrus), e Cupressus sp. (cipreste). Estas espécies juntas somam $40 \%$ da flora arbórea das quatro escolas. Estas espécies não são nativas, mas apenas o ligustro apresenta potencial invasor para o bioma local.

Apenas $4,33 \%$ dos espécimes inventariados contêm epífitas, sendo que em sua maioria, estas são da espécie Microgramma vaccinifolia chamada popularmente de samambaia - grama.

\section{REFERÊNCIAS BIBLIOGRÁFICAS}

BACKES, P; IRGANG, B. Árvores Cultivadas no Sul do Brasil: Guia de Identificação e Interesse Paisagístico das Principais Espécies Exóticas. Porto Alegre. Clube da Árvore: 2004.

BIONDI, D; ALTHAUS, M. Árvores de Rua de Curitiba: Cultivo e Manejo. Curitiba: FUPEF: 2005.

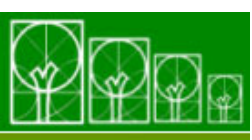


CADORIN, D. A, SILVA, L. M. HASSE, I, BETT, F. C, EMER, A. A, OLIVEIRA, J. R. Características da arborização dos bairros Cadorin, Parzianello e La Salle em Pato Branco PR/2007. Revista da Sociedade Brasileira de Arborização Urbana, Piracicaba, v. 3, p. 40-52, 2008.

CARVALHO, P. R. E. Espécies Arbóreas Brasileiras. Brasília: Embrapa Informação Tecnológica, 2003.

ELALI, G. O ambiente na escola: uma discussão sobre a relação escola-natureza em educação infantil. Estudos de Psicologia, v. 8, n. 2, p.309-319, 2003.

EMBRAPA. EMPRESA BRASILEIRA DE PESQUISA AGROPECUÁRIA. Centro Nacional de Pesquisa de Solos. Sistema Brasileiro de Classificação de Solos. Brasília: EMBRAPA, 1999. $412 \mathrm{p}$.

FEDRIZZI, B; TOMASINI, S.L.V; CARDOSO, L. M. A vegetação no pátio escolar: um estudo para a realidade de Porto Alegre-RS. Revista Brasileira de arborização urbana. Disponível em <http://www.sbau.org.br/index> Acesso em 24 de maio de 2008.

FILHO, L. A. J; PAIVA, N. H; GONÇALVES, W. Paisagismo: princípios básicos. Viçosa: Aprenda Fácil, 2001.

GIONG, C; WAECHTER, L. J. Composição Florística e Estrutura Comunitária de Epífitos Vasculares em uma Floresta de galeria na Depressão Central do Rio Grande do Sul. Revista Brasileira de Botânica, São Paulo, v.27, n.3, 2004.

GREY, G. W.; DENEKE, F. J. Urban Forestry. 2.ed. New York: John Wiley, 1986. 299p.

IAP - Instituto Ambiental do Paraná. Lista Oficial de Espécies Exóticas Invasoras para o Estado do Paraná. 2007. Disponível em: http://www.pr.gov.br/iap. Acesso em: 21/08/09.

IAPAR - INSTITUTO AGRONÔMICO DO PARANÁ. Cartas climáticas do Paraná. Londrina: IAPAR, 2000. CD-ROM.

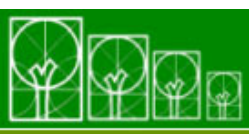


IBGE. Manual técnico da vegetação brasileira. Rio de Janeiro: Fundação Instituto Brasileiro de Geografia e Estatística, Série Manuais Técnicos em Geociências, 1992. 92p.

IBGE. Atlas do senso demográfico. Rio de Janeiro: IBGE, 2000. 127p.

IBGE. Dimensão Ambiental - BIODIVERSIDADE. Rio de Janeiro: Fundação Instituto Brasileiro de Geografia e Estatística, Série Manuais Técnicos em Geociências, 2004. 134p.

IBGE. Mapa de Biomas e de Vegetação. Disponível<http://www.ibge.gov.br/home/presidencia/noticias/noticia_visualiza.php?id_notici $a=169>$ Acesso em 12/08/2008.

INSTITUTO HÓRUS DE DESENVOLVIMENTO E CONSERVAÇÃO AMBIENTAL. Espécies exóticas invasoras: fichas técnicas. 2006. Disponível em: http://www.institutohorus.org.br. Acesso em: 13/04/2009.

LEFF, E. As Universidades e a Formação Ambiental na América Latina. In: Cadernos de Desenvolvimento e Ambiente, Curitiba, n.2, 1995.

MACHADO, R, R, B et al. Árvores Nativas para a Arborização de Teresina - PIAUÍ. Revista da Sociedade Brasileira de Arborização Urbana, Piracicaba, v.1, n.1, p. 10-18, 2006.

MELO, Q.R.F.E; SEVERO, A.M.B. Vegetação Arbórea do Campus da Universidade de Passo Fundo. Revista da Sociedade Brasileira de arborização urbana, Piracivaba, v.2, n.2, 2007.

PEREIRA G. A et al. O uso de espécies vegetais, como instrumento de biodiversidade da avifauna silvestre, na arborização pública: o caso do recife. Atualidades ornitológicas, n.125, p. 10, 2005.

REIS, A.; ANJOS, A.; LESSA, A. P.; BECHARA, F. Critérios para a seleção de espécies na arborização ecológica. Sellowia, Itajaí, v. 53, n. 55 pág. 51-67, 2003. 
RIBEIRO, L. M. O papel das representações sociais na educação ambiental, 2003. Dissertação. (Mestrado em Educação). PUC. Rio de Janeiro, 2003.

RODIGHIERO, D. A; SILVA, L. M. Infra-estrutura urbana e arborização em três bairros de Pato Branco/PR. In: XII Seminário de Iniciação Científica e Tecnológica da UTFPR, 2007, Anais...Curitiba: UTFPR, CD-ROM.

SANTOS, N. R. Z; TEIXEIRA, I. F. Arborização de Vias Públicas: Ambiente x Vegetação. Santa Cruz do Sul: Instituto Souza Cruz, 2001. 135p.

SILVA, L. M. ; HASSE, I. ; MOCCELLIN, R; ZBORALSKI, A. R. Arborização de vias públicas e a utilização de espécies exóticas: o caso do bairro centro de Pato Branco/PR. Scientia Agrária, Curitiba, v. 8, p. 47-53, 2007.

SILVA. L, M et al. Inventário da Arborização em duas Vias de Mariópolis/ PR. Revista da Sociedade Brasileira de Arborização Urbana, Piracicaba, v.3, n.1, p. 36-53, 2008a.

SILVA. L, M. Reflexões sobre a Identidade Arbórea das Cidades. Revista da Sociedade Brasileira de Arborização Urbana, Piracicaba, v.3, n.3, p. 65-71, 2008b.

ZILLER, S. R. Plantas Exóticas Invasoras: a Ameaça da Contaminação Biológica. Revista Ciência Hoje, Rio de Janeiro, v.30, n.178, p. 77-79, 2001. 